\title{
WLTP fordert bessere Aerodynamik
}

Liebe Leserin, lieber Leser,

der Themenbereich RDE und WLTP ist sehr komplex, da die Rahmenbedingungen im Fahrbetrieb durch Umweltbedingungen, Route, Fahrstil und Kraftstoffe eine erhebliche Rolle spielen. Aufgrund des enormen Leistungsüberschusses der meisten Pkw sind die aus den Gesetzgebungen $\mathrm{zu} \mathrm{CO}_{2}$-Emissionen und Luftqualität resultierenden Herausforderungen nur systemisch im Zusammenspiel Antrieb und Gesamtfahrzeug zu lösen.

Sogenannte Worst-Case- $\mathrm{CO}_{2}$-Angaben werden Pflicht, individuelle $\mathrm{CO}_{2}$-Angaben für einzelne Fahrzeuge und Varianten sind erlaubt. Sonderausstattungen müssen dadurch optimiert werden. Längere Zyklusdauer, größere Beschleunigung und höhere Geschwindigkeit bilden einen deutlich realistischeren Fahrzyklus ab. Dadurch nimmt der Einfluss elektrischer Verbraucher ab, der Beitrag des Luftwiderstands - und damit die Relevanz der Aerodynamik in der Fahrzeugentwicklung - jedoch erheblich zu. Nimmt man an, dass die Rekuperationsfähigkeit von Fahrzeugen durch den WLTP auf $50 \%$ gesteigert wird, so erhöht sich der Beitrag der Aerodynamik quer durch alle Fahrzeugklassen um etwa 10 bis $12 \%$. Das bedeutet, dass Sonderausstattungen zukünftig genauer bewertet werden müssen, ein höherer Aufwand bei Ausrollversuchen betrieben werden muss, eine stärkere Familienbildung innerhalb eines Fahrzeugtyps erfolgen wird und Ersatzversuche im Windkanal unumgänglich sein werden.

Da viele Kunden wohl eher nicht bereit sind, auf liebgewonnene Ausstattungsmerkmale zu verzichten, rücken Räder, Anbauteile und auch die Kühlung stärker in den Fokus. Es wird mithin ein ganzes Bündel an Maßnahmen zur Senkung der
Luftwiderstandskraft nötig sein. Hierzu zählen beispielsweise eine Optimierung der Umströmungen bei Rädern, am Unterboden und an den Außenspiegeln sowie eine spezielle Gestaltung der Außenhäute und eine bedarfsgesteuerte Kühlluftführung. Aktive Aerodynamikmaßnahmen wie zum Beispiel aktiver Spoiler und Niveauregulierung könnten zukünftig auch in mittlere und kleinere Fahrzeugkategorien Einzug halten.

Der gesellschaftliche Wertewandel führt dazu, dass zukünftig eines der entscheidenden Kriterien für Erfolg oder Misserfolg sein wird, wie stark der ökologische Fußabdruck eines Fahrzeugs und damit einer Marke ist. Dies könnte der Kunde bald schon bei der Konfiguration seines Neufahrzeugs selbst in der Hand haben.

Beste Grüße,

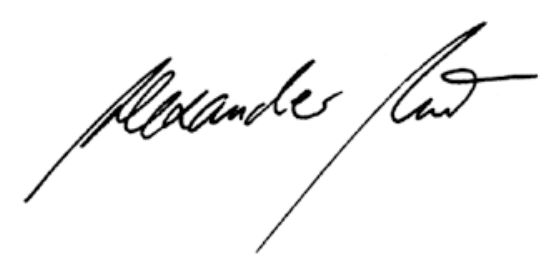

Dr. Alexander Heintzel

Chefredakteur

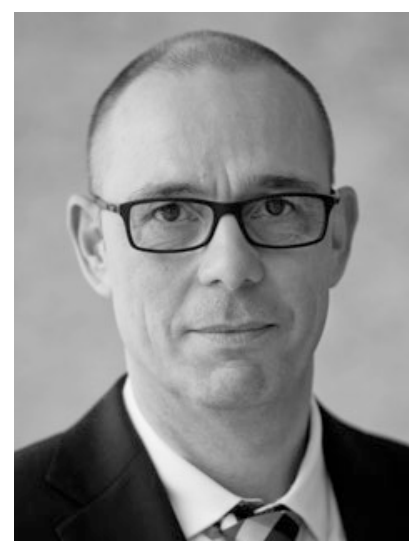

\section{DRAXLMAIER}

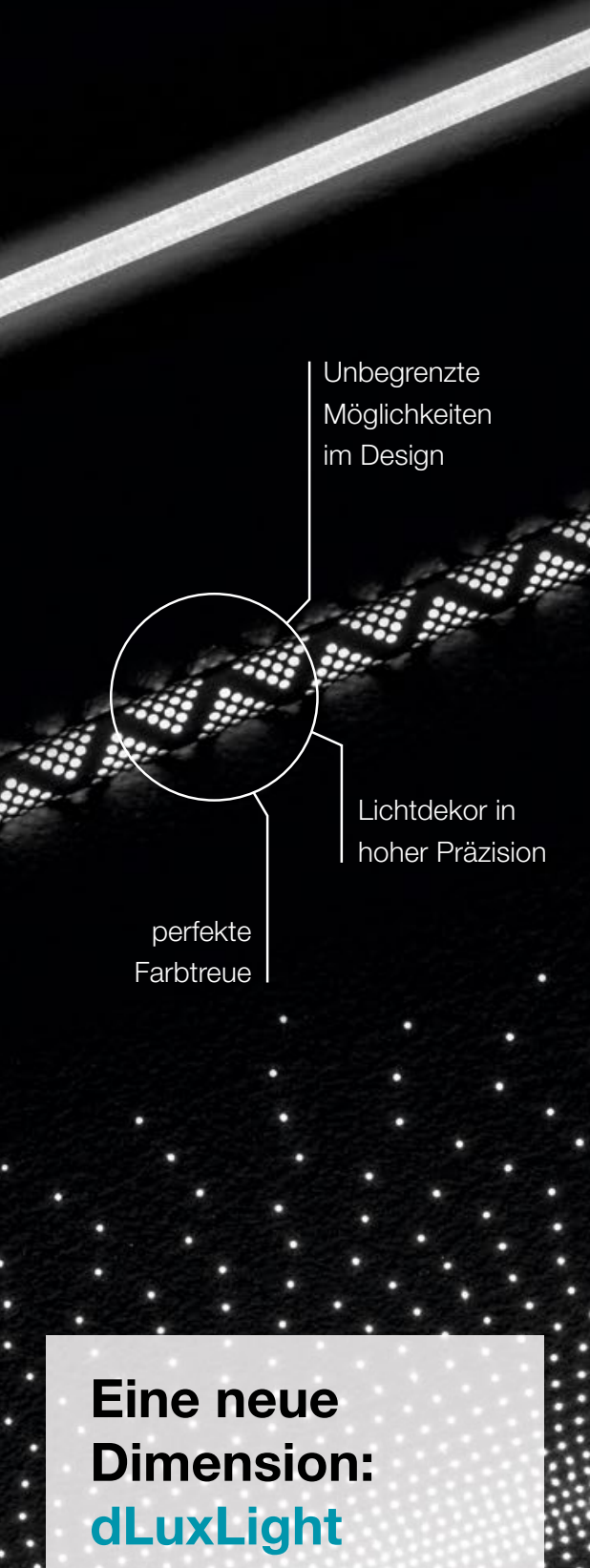
\section{anspruchsvolle Kunden}

Markentypische Linienverläufe und Konturen im Fahrzeuginterieur bei Nacht betonen. Homogene Linienbeleuchtung ohne Schwankungen in Helligkeit und Farbe über die gesamte Fahrzeuglebensdauer. Exklusives Ambiente durch hinterleuchtetes Leder. Stimmungsvolle und individuelle Lichtszenarien bietet die Produktfamilie dLuxLight der DRÄXLMAIER Group. www.draexImaier.com / ambientelicht 